\title{
Imágenes obtenidas mediante tomografía espiral multicorte (TEM) en infecciones del sistema nervioso central, Instituto Nacional de Ciencias Neurológicas
}

Images obtained by multislice spiral tomography in central nervous

system infections, Neurologic Sciences National Institute

Dario Esteban Arias ${ }^{1,2}$

${ }^{1}$ Medico Neuroradiólogo del Instituto Nacional de Ciencias Neurológicas, Lima, Perú.

${ }^{2}$ Departamento Académico de Microbiología, Facultad de Medicina, Universidad Nacional Mayor de San Marcos, Lima, Perú.

Las siguientes imágenes de tomografía espiral multicorte (TEM) cerebral corresponden a pacientes que han sido atendidos en el Instituto Nacional de Ciencias Neurológicas. El diagnóstico final ha sido verificado en sus respectivas historias clínicas y/o mediante el resultado de anatomía patológica.
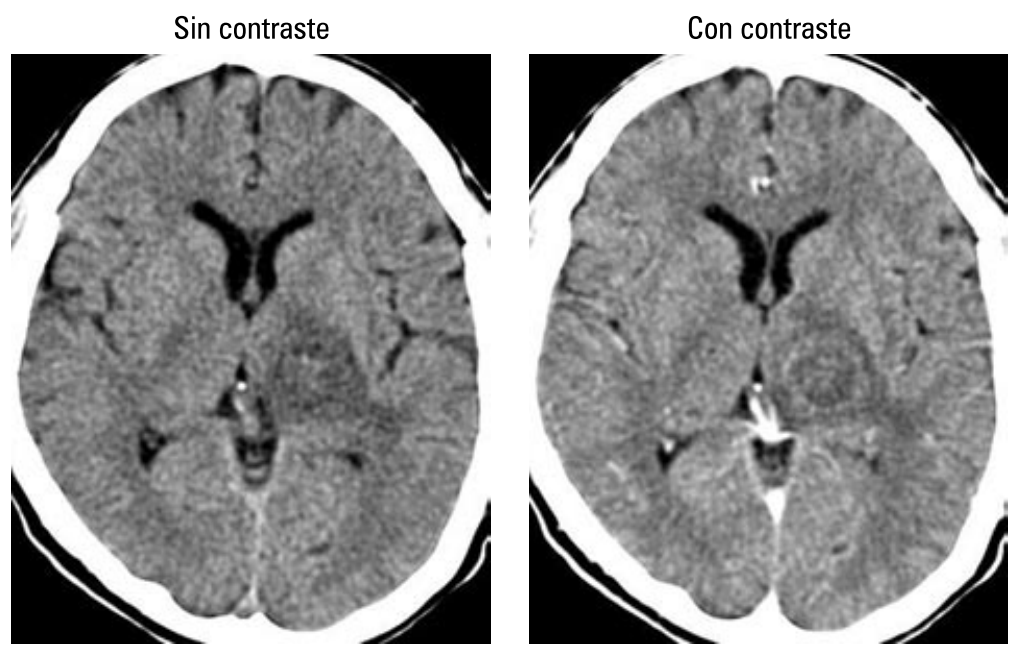

Figura 1. Toxoplasmosis en núcleo basal. En la fotografía de la izquierda se observa una imagen ovalada, hipodensa y homogénea. En la fotografía de la derecha se muestra una tenue imagen anular debido a la captación de sustancia de contraste con edema perilesional $^{(1)}$. 


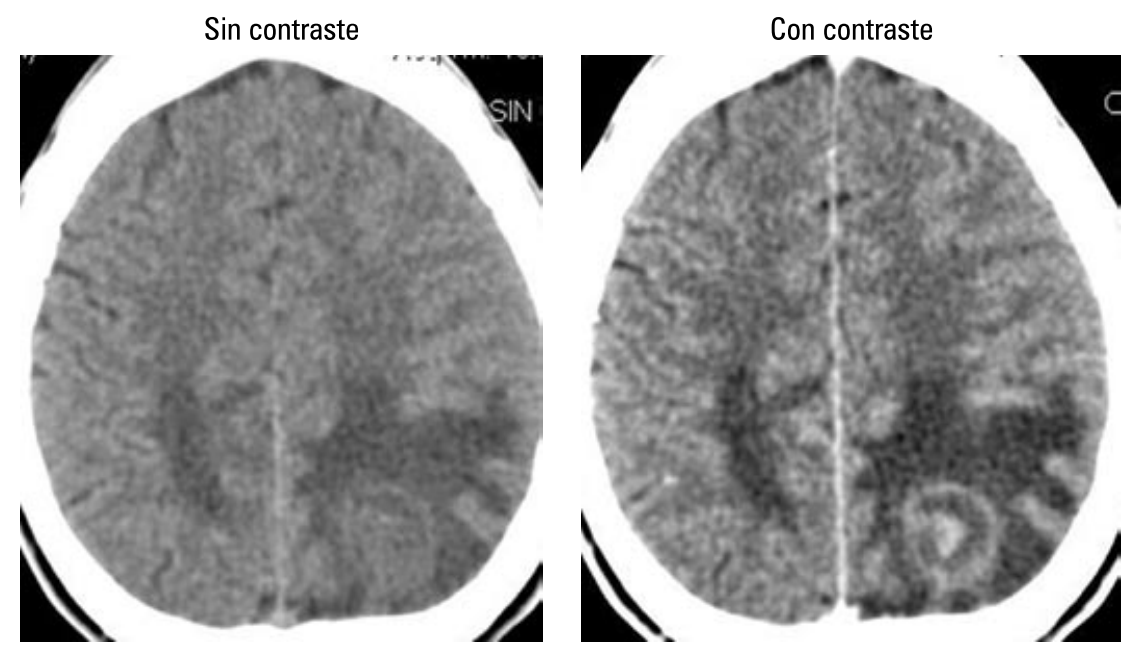

Figura 2. Toxoplasmosis localizada a nivel córtico subcortical del lóbulo parietal. En la fotografía de la izquierda se aprecia imagen ovalada de leve hiperdensidad con edema perilesional. En la fotografía de la derecha aparece una imagen anular hiperdensa y otra amorfa en el interior de ella, ambas debido a la captación de la sustancia de contraste, denominado 'signo de diana' (1).

Figura 3. Granuloma tuberculoso localizado en sustancia blanca periventricular. En la fotografía de la izquierda se evidencia imagen de bordes irregulares de leve hiperdensidad. En

la fotografía de la derecha el borde se realza con el contraste de manera heterogénea ${ }^{(1,2)}$
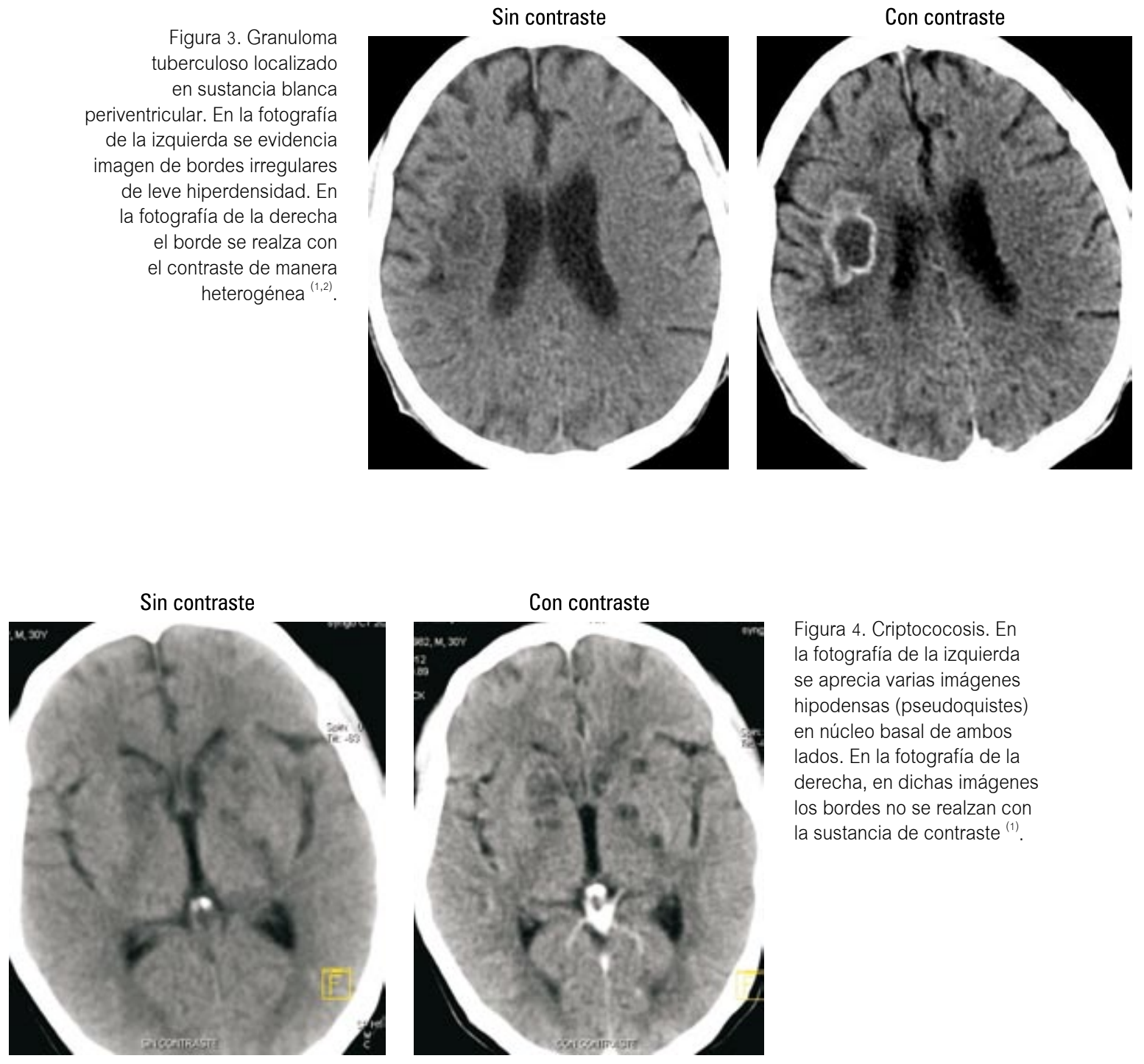

Figura 4. Criptococosis. En la fotografía de la izquierda se aprecia varias imágenes hipodensas (pseudoquistes) en núcleo basal de ambos lados. En la fotografía de la derecha, en dichas imágenes los bordes no se realzan con la sustancia de contraste ${ }^{(1)}$. 


\section{ABSCESO BACTERIANO.}

Figura 5. Absceso bacteriano. En la fotografía de la izquierda la cápsula de la lesión muestra imagen hiperdensa, delgada, de bordes definidos. El contenido hipodenso se debe a la necrosis parenquimal. En la fotografía de la derecha el borde se realza de manera uniforme con el contraste, asociado a edema perilesional ${ }^{(3)}$.
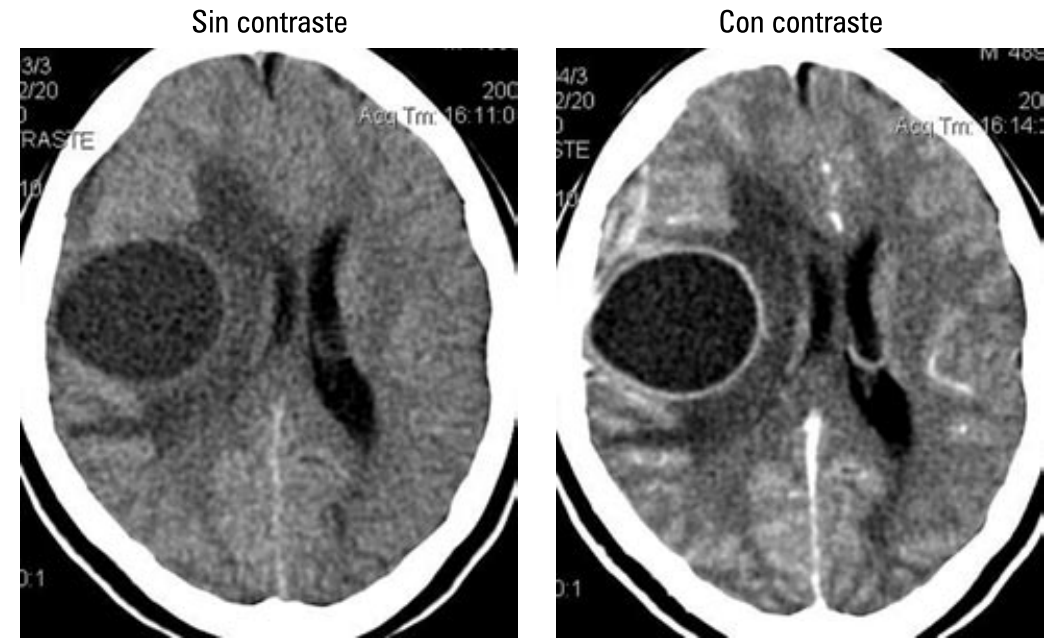

\section{NEUROCISTICERCOSIS.}
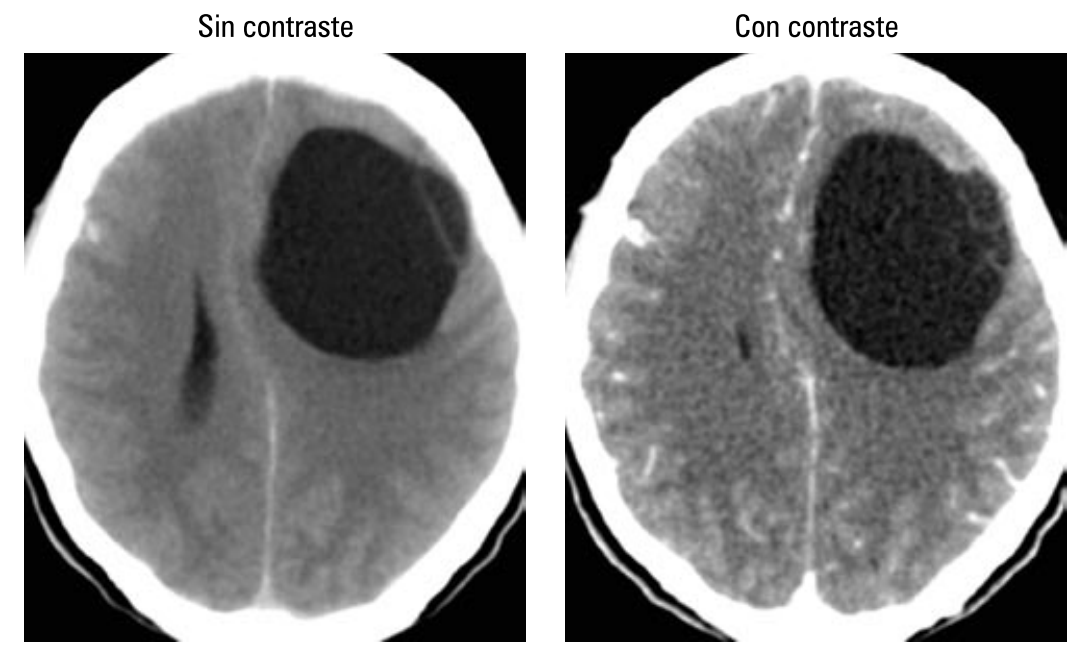

Figura 6. Cisticerco

gigante. En la fotografía de la izquierda se

aprecia imagen hipodensa (líquido) de bordes definidos. En la fotografía de la derecha el borde no se realza con la sustancia de contraste ${ }^{(4)}$.

\section{Figura 7. Cisticerco fase vesicular y calcificada, TEM sin contraste. Se observa varias imágenes ovaladas hipodensas (líquido) de bordes definidos, algunas con imagen puntiforme en su interior, que corresponde al escólex, sin edema perilesional; también \\ se aprecia nódulos calcificados (imágenes hiperdensas) ${ }^{(4)}$.}
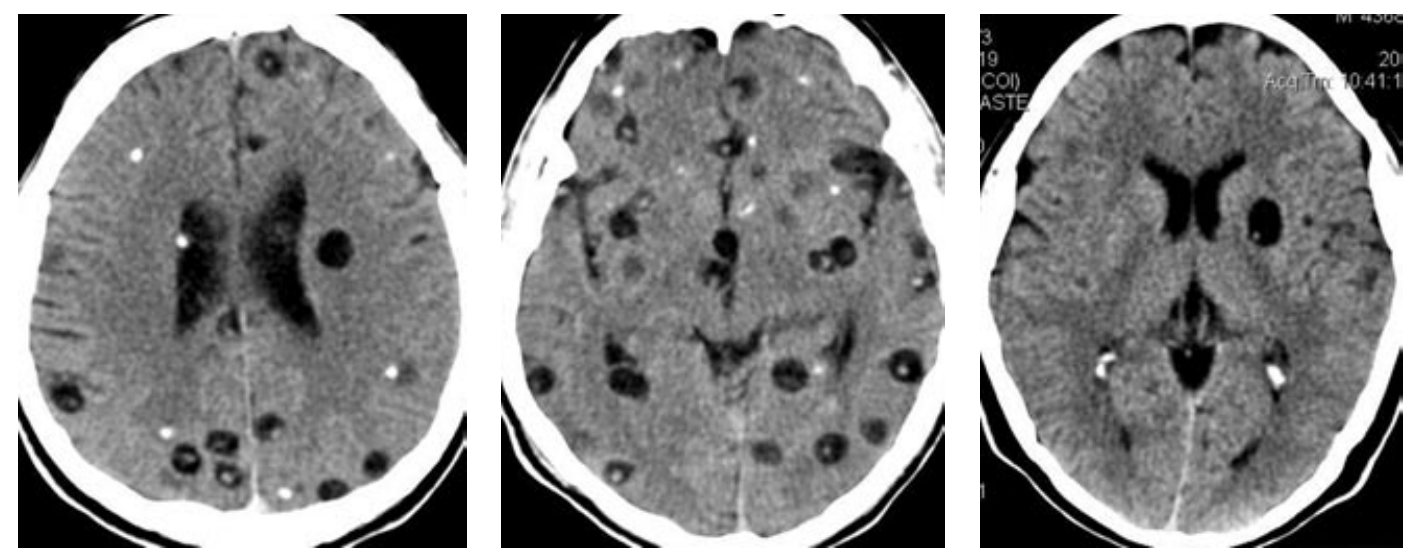
4. HIDATIDOSIS.
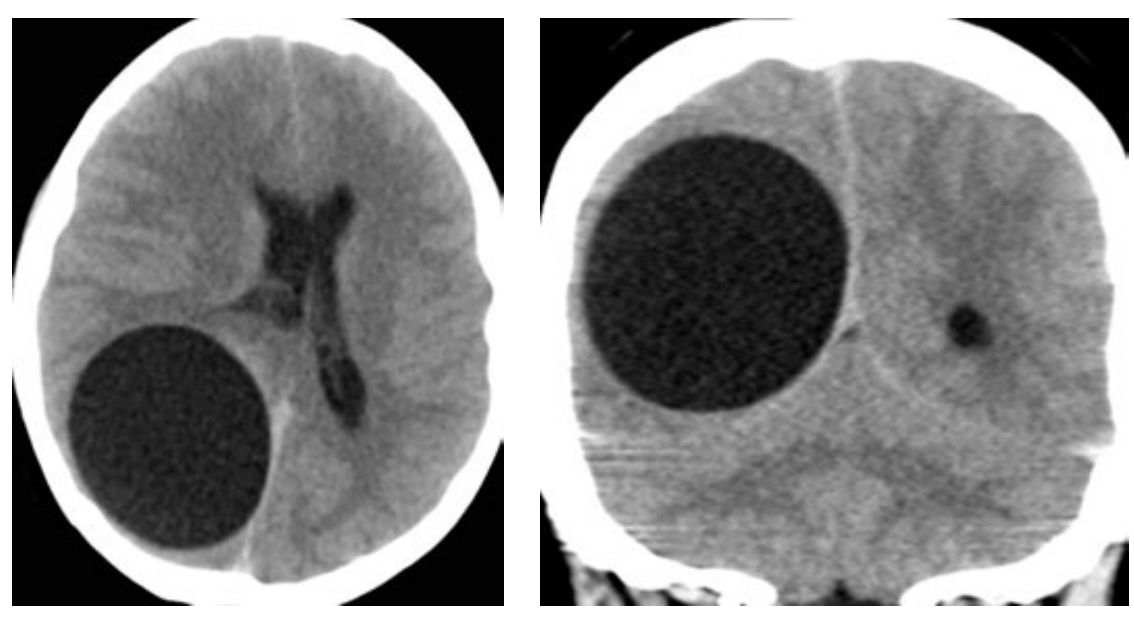

Figura 8. Quiste

hidatídico

intraparenquimal.

TEM sin contraste.

Se observa imagen hipodensa (líquido) de bordes definidos, sin calcificaciones en el borde ni edema perilesional ${ }^{(2)}$.

\section{TUBERCULOSIS EN PACIENTES INMUNOCOMPETENTES.}

Figura 9. Granuloma tuberculoso nodular. En la fotografía de la izquierda se aprecia imagen ovalada

hiperdensa en región cortical de lóbulo parietal, con edema perilesional. En la fotografía de la derecha dicha imagen se realza de manera homogénea con el contraste $^{(2)}$
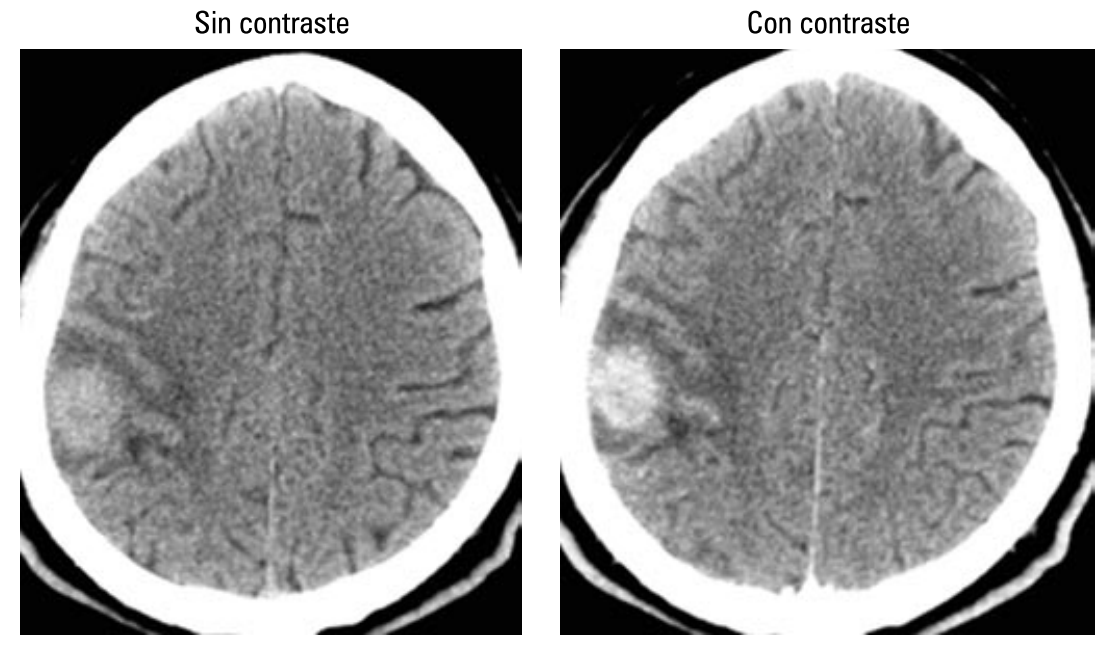

\section{REFERENCIAS BIBLIOGRÁFICAS}

1. Corti M, Villafañe M, Palmieri O, Yampolsky Cl, Millet G. Aporte de las neuroimágenes al diagnóstico del compromiso del sistema nervioso central en la enfermedad HIV/sida. RAR. 2007;71(1):37-44.

2. Polat P, Kantarci M, Alper F, Suma S, Koruyucu M, Okur A. Hydatid disease from head to toe. Radio Graphics. 2003;23:475-94.
3. Harisinghani M, McLoud T, Shepard A, Ko J, Shroff M, Mueller P. Tuberculosis from head to toe. Radio Graphics. 2000;20:449-70.

4. Fica A, Bustos P, Miranda G. Absceso cerebral. A propósito de una serie de 30 casos. Rev Chil Infect. 2006;23(2):140-9.

5. Borbon A, Alvaro J, Schmidt V. Neurocisticercosis: hallazgos imaginológicos en tomografía computarizada. Revisión de la literatura y reporte de dos casos. Rev Colomb Radiol. 2008;19(4):2528-33.
Financiamiento:

Recursos propios del autor.

No existen conflictos de intereses

Correspondencia:

Dario Esteban Arias

Correo electrónico: dario.esteban.a@gmail.com 